\title{
Um olhar quantitativo sobre a escolha discente pelo programa de pós- graduação em extensão rural
}

\author{
A Quantitative Look Upon The Choice Of The Post-Graduation Students In Rural Extension On The Choice By \\ Students Graduate Programme In Rural Extension: A Quantitative Exame
}

\author{
Mauro Barcellos Sopeña', André de Oliveira², lolanda Araujo Ferreira dos Santos³ ${ }^{3}$ Andréa Cristina Dörr ${ }^{4}$ \\ 'Prof. Assistente do Departamento de Economia/UNIPAMPA. Doutorando do Programa de Pós-Graduação em Extensão Rural/UFSM. \\ Universidade Federal de Santa Maria - RS - Brasil \\ ${ }^{2}$ Eng. Agrônomo. Mestrando do Programa de Pós-Graduação em Extensão Rural/UFSM. Universidade Federal de Santa Maria - RS - Brasil \\ ${ }^{3}$ Eng. de Pesca. Mestranda do Programa de Pós-Graduação em Extensão Rural/UFSM - RS - Brasil \\ ${ }^{4}$ Profa. Adjunta do Departamento de Educação Agrícola e Extensão Rural/UFSM - RS - Brasil
}

\begin{abstract}
Resumo
O trabalho analisa o perfil de alunos de pós-graduação e os fatores determinantes da escolha por cursos na área de pesquisa social que relacionam-se ao meio rural. O público-alvo refere-se aos alunos de pós-graduação em Extensão Rural e Residência Agrária da Universidade Federal de Santa Maria, Brasil. Com o uso de uma abordagem quantitativa, a pesquisa viabilizou a análise de diferentes categorias que permitiram conclusões acerca daquelas escolhas. Os resultados permitem verificar o perfil dos alunos por nível de pós-graduação e os determinantes das escolhas a partir de diferentes elementos e variáveis. Em linhas gerais, a maioria dos alunos é oriunda de cursos de ciências rurais, não possui religião e apresenta renda superior a cinco salários mínimos. Outros resultados apontam para o predomínio da escola pública na formação principal dos alunos e elevado registro de trabalho rural na família. Dentre os resultados apontados, conclui-se que para os formados em ciências rurais, a vocação parece representar o grande motivo pela escolha profissional.
\end{abstract}

Palavras-chave: Pesquisa Social, Cursos de Ciências Rurais, Escolha Profissional.

\begin{abstract}
The paper analyzes the profile of students postgraduate and determinants of choice for courses in social research that relate to rural areas. The target group refers to the students of the Federal University of Santa Maria, Brazil. Using a quantitative approach, the research made possible the analysis of different categories that allowed conclusions about those choices. The overall results allow you to check the profile of students by level of postgraduate and determinants of choices from different elements and variables. In general, most students come from rural sciences courses, has no religion and have income over five salaries. Other results point to the prevalence of the public school education of students in primary and high record of rural labor in the family. Among the indicated results, it is concluded that for graduates in rural sciences, vocation seems to represent the major reason for vocational choice.
\end{abstract}

Keywords: Social Research, Courses of Agricultural Sciences, Professional Choice. 


\section{INTRODUÇÃO}

A escolha por cursos de pós-graduação na área social é cercada por muitos determinantes. Ocorrências desta natureza são observadas em muitos programas da área da pesquisa social voltada para o mundo rural, notadamente no Estado do Rio Grande do Sul. Em outros campos do conhecimento igualmente se pode verificar tal fenômeno. Dados relativos à formação principal de alunos dos cursos de pós-graduação em Extensão Rural (UFSM), Agronegócio (UFRGS) e Desenvolvimento Rural (UFRGS) demonstram que, em 2010, 50,0\% do primeiro eram oriundos de cursos como agronomia ou medicina veterinária. No Programa de Agronegócio da UFRGS, os alunos possuíam formação principal muito diversificada, com 13 diferentes áreas registradas. No mestrado, eram 23 registros distintos. A pesquisa em desenvolvimento rural, da mesma instituição, não disponibiliza dados sobre a formação de seus alunos, mas indica que a diversidade de origem e formação dos discentes é uma importante, e desejada, característica do Programa (PGDR, 2013).

Embora não se pretenda realizar uma análise epistemológica e conceitual da pesquisa social, tal conceito deve ser minimamente referido enquanto área de pesquisa. Assim, do ponto de vista positivista da ciência, a pesquisa social compreende processos formais neutros, sistemáticos e metódicos de apreensão da realidade. Trabalha-se neste artigo com esta definição ampla, entendendose que a pesquisa social vinculada ao meio rural trata, portanto, das diferentes realidades sociais do mundo rural por meio de um viés científico ortodoxo $^{1}$. GIL (2009, p. 26) sinaliza esta definição da seguinte forma:

Processo formal e sistemático de desenvolvimento do método científico. O objetivo fundamental da pesquisa é descobrir respostas para problemas mediante o emprego de procedimentos científicos. A partir dessa

\footnotetext{
1. Não há, contudo, consenso estabelecido acerca desta definição. Em CHIZZOTTI (2003), por exemplo, se pode encontrar ampla análise que contesta a neutralidade da ciência própria do positivismo e, assim, concebe o conhecimento científico de uma perspectiva diferente daquela usualmente adotada pelo positivismo. Em trabalho de Holland (1983, apud DESLANDES, 1997, p. 104), o paradigma positivista, outrora hegemonico nesse campo, passa a ser questionado por diversos pensadores, que apontam a subjetividade inerente a qualquer avaliação. A pretensa objetividade passa a ser percebida como limitada pelos vários recortes produzidos pelo investigador. Decisões que dizem respeito a quais informações devem ser coletadas, escolha da amostra, seleção de critérios e princípios, métodos de tratamento estatístico, passam a ser percebidos como envolvendo julgamentos de valor.
}

conceituação, pode-se, portanto, definir pesquisa social como o processo que, utilizando a metodologia científica, permite a obtenção de novos conhecimentos no campo da realidade social.

Em termos mais específicos, se pode conceber a realidade social em sentido bastante amplo, envolvendo todos os aspectos relativos ao homem em seus múltiplos relacionamentos com outros homens e instituições sociais GIL $(2009$, p. 26). A pesquisa social voltada ao meio rural é entendida, portanto, nestes termos. A escolha dos alunos, motivação deste trabalho, igualmente se refere ao desejo de explicar as relações e fenômenos sociais que se estabelecem na realidade rural.

Esta pesquisa justifica-se por dois motivos principais: (a) é recorrente a noção de que importante parcela de alunos de graduação demandam estudos e pesquisas nas áreas sociais voltadas às questões rurais. O estudo dos determinantes destas escolhas, portanto, mostra-se pertinente. De outro lado, (b) a riqueza da pesquisa na área parece representar fator determinante da decisão daquele público. Embora se reconheça a importância que um estudo sobre escolha profissional e pesquisa social possa suscitar no âmbito da educação ou da sociologia, o presente artigo procura oferecer elementos e interpretações estatísticas que não contemplam tais perspectivas. Dessa forma, este trabalho objetiva investigar quais são as características deste público-alvo como forma de identificar possíveis determinantes da escolha por cursos de pós-graduação na área de pesquisa social que se vincule à área rural.

Esta pesquisa justifica-se por dois motivos principais: (a) é recorrente a noção de que importante parcela de alunos de graduação demandam estudos e pesquisas nas áreas sociais voltadas às questões rurais. $\mathrm{O}$ estudo dos determinantes destas escolhas, portanto, mostra-se pertinente. De outro lado, (b) a riqueza da pesquisa na área parece representar fator determinante da decisão daquele público. Embora se reconheça a importância que um estudo sobre escolha profissional e pesquisa social possa suscitar no âmbito da educação ou da sociologia, o presente artigo procura oferecer elementos e interpretações estatísticas que não contemplam tais perspectivas. Dessa forma, este trabalho objetiva investigar quais são as características deste público-alvo como forma de identificar possíveis determinantes da escolha por cursos de pós-graduação na área de pesquisa social que se vincule à área rural.

Ao analisar a população formada por alu- 
nos do Programa de Pós-Graduação em Extensão Rural da Universidade Federal de Santa Maria $\left(\mathrm{PPGExR}^{2}\right)$, Brasil, o estudo conta com abordagem quantitativa realizada a partir de dados primários e embasada em literatura própria da pesquisa em ciências sociais. Os resultados permitem verificar o perfil dos alunos por nível de pós-graduação e os determinantes das escolhas a partir de diferentes elementos e variáveis. O PPGExR foi fundado em 1975, inicialmente denominado como Curso de Pós-Graduação em Educação Agrícola e Extensão Rural. Em 2007 esse programa aprovou o primeiro curso de doutorado em Extensão Rural da América Latina, com o ingresso dos primeiros doutorandos em março de 2008. O PPGExR, faz parte do Departamento de Educação Agrícola e Extensão Rural, no Centro de Ciências Rurais da Universidade Federal de Santa Maria. Além dos níveis de mestrado e doutorado o PPGExR oferece ainda o Curso de Especialização em Agricultura Familiar Camponesa e Educação do Campo - o Residência Agrária. Este último, que também faz parte do estudo em questão tem como público alvo assentados de reforma agrária com nível superior, técnicos que trabalham com assistência técnica e extensão rural, e egressos de diversos cursos de graduação.

\section{MATERAIS E MÉTODOS}

\section{I uso de questionários na coleta de dados}

Considerando a existência de diferentes técnicas de coleta de dados, o que determinará a escolha de um meio particular entre vários outros é a característica da pesquisa que se deseja conduzir. Entrevistas, formulários e questionários representam algumas das modalidades utilizadas ${ }^{3}$. Nesta última, escolhida para conduzir a presente pesquisa, a tarefa principal

consiste basicamente em traduzir objetivos da pesquisa em questões específicas[...] o que requer uma série de cuidados, tais

2. Localização: latitude: $29^{\circ} 43^{\prime} 06.09^{\prime \prime}$ S e longitude: $053^{\circ} 43^{\prime}$ 03.93" W.

3. Enquanto nos questionários o próprio respondente produz as respostas, no formulário o pesquisador as constrói. Segundo Marsiglia, o questionário constitui-se de uma série ordenada de perguntas referentes ao tema de pesquisa. [...] Quando o próprio pesquisador aplica pessoalmente o instrumento nos pesquisados, este é denominado de Formulário. Os questionários e formulários apresentam perguntas objetivas, muitas vezes com alternativas de respostas já codificadas, mas podem conter também algumas perguntas abertas. Antes de serem aplicados os formulários ou enviados os questionários, o instrumento de coleta deve passar por um pré - teste [...] (MARSIGLIA, 2007, p. 10). como: constatação de sua eficácia para verificação dos objetivos; determinação da forma e do conteúdo das questões; quantidade e ordenação das questões; construção das alternativas; apresentação do questionário e pré-teste do questionário (GIL, 2009, p. 121).

A clareza e objetividade importam na construção dos instrumentos de pesquisa. Para BARBETTA (2012, p. 32), a construção de um questionário é uma etapa longa que deve ser executada com muita cautela. A realização de pré-testes (ou pré-testagem) representa, portanto, um meio adequado de se verificar sua aplicabilidade antes de se iniciar a coleta dos dados. Segundo GIL (2009, p. 134), o pré-teste é realizado mediante a aplicação de alguns questionários (de 10 a 20) a elementos que pertencem à população pesquisada. Para o autor, o pré-teste deverá assegurar a funcionalidade do instrumento no que se refere a a) clareza e precisão dos termos; b) forma de questões; c) desmembramento das questões; d) ordem das questões; e e) introdução do questionário (GIL, 2009, p. 134).

CHIZZOTTI $(1995$, p. 56) considera central para a plena obtenção de seus resultados, que a pesquisa conduzida por meio de questionários obedeça a uma estrutura lógica. Ademais, na confecção de seus instrumentos, devem-se evitar ambiguidades, dúvidas ou incompreensões, recusas e "não sei", e produzir respostas curtas, rápidas e objetivas. Em adição a estas precauções, a definição da forma como as questões serão propostas aos integrantes do estudo é necessária. Em linhas gerais, as questões podem ser abertas, fechadas ou dependentes. Em questões abertas, o participante da pesquisa possui condições de construir sua resposta. Ao contrário, na forma fechada, se disponibiliza alternativas para que o pesquisado realize sua escolha (FREITAS; MOSCAROLA, 2002). No modelo dependente de questão, observase uma relação entre duas ou mais questões (uma resposta pode ou não estar condicionada a outra).

A aplicação de questionários como fonte de dados primários, embora mais custosa (quando comparada com a seleção de informações secundárias), apresenta vantagens que devem ser destacadas. Para GRAY (2012 p. 275), pode-se utilizar um questionário quando, o público for relativamente grande e onde forem preciso usar perguntas padronizadas, o questionário é ideal e permitirá, se for necessário, uma abordagem analítica explorando as relações entre as variáveis.

Pelo exposto, fica evidente que a aplicação 
deste instrumento de pesquisa requer cuidados e procedimentos fundamentais em seu uso. Esforços na construção de perguntas que atendam aos objetivos da pesquisa de forma clara e objetiva devem ser perseguidos. De outro lado, a realização de pré-testes ou pilotos podem garantir a funcionalidade do instrumento, proporcionando maior segurança ao pesquisador. A construção deste meio de pesquisa, enfim, pode ser exitosa na busca de dados primários valiosos ao estudo que se queira conduzir. Neste sentido, as categorias de análise utilizadas fazem parte das questões formuladas no questionário e são, a seguir, melhor indicadas.

\section{2 tratamento quantitavo dos dados}

Do ponto de vista metodológico, o presente artigo caracteriza-se como uma pesquisa quantitativa de caráter exploratório que pretende inferir quais características do público-alvo são determinantes para a realização de escolhas de pósgraduação na área social. Para tanto, demostra-se a seguir quais procedimentos metodológicos foram utilizados, bem como de que forma foi situada no tempo e no espaço. A Figura 1 demonstra as etapas da pesquisa.

A escolha do questionário como instrumento de coleta de dados, seguiu-se com a elaboração de dez questões fechadas e direcionadas aos objetivos do trabalho. Pela disposição das questões, o respondente opta por uma entre várias alternativas possíveis. Outras três questões abertas, de natureza contínua, formam o conjunto elaborado de questões. As categorias de análise, presentes no questionário, foram distribuídas, portanto, em 13 perguntas. Entende-se que tais elementos possibilitam a análise do perfil dos estudantes, ao mesmo tempo em que permitem explorar condicionantes acerca da relação entre a escolha de formação profissional e o ingresso em um programa de pós-graduação vinculado à pesquisa social.

Embora o elenco de categorias apresente limitações, sustenta-se que este é um fenômeno inerente a toda e qualquer pesquisa, especialmente quando se compreende a necessidade de delimitações que todo e qualquer estudo está sujeito. De outro lado, a possibilidade de cruzamento dos dados não deve ser desprezada, o que amplia o leque de inferências que se pode realizar acerca do objeto de estudo. As categorias de análise, portanto, correspondem a um conjunto de variáveis categóricas contínuas. As variáveis categóricas são:

a) curso que está realizando; b) área da graduação; c) relação entre a pós-graduação e a formação de origem; d) ocorrência de trabalho no meio rural na família; e) determinante da escolha pelo curso de graduação; f) atividade extraclasse mais representativa no período de graduação; g)

\section{FIGURA 1: PROCEDIMENTOS METODOLÓGICOS DA PESQUISA}

\section{Determinação da População \\ (Público-alvo do trabalho)}

\begin{abstract}
Questionário (elaboração)
\end{abstract}

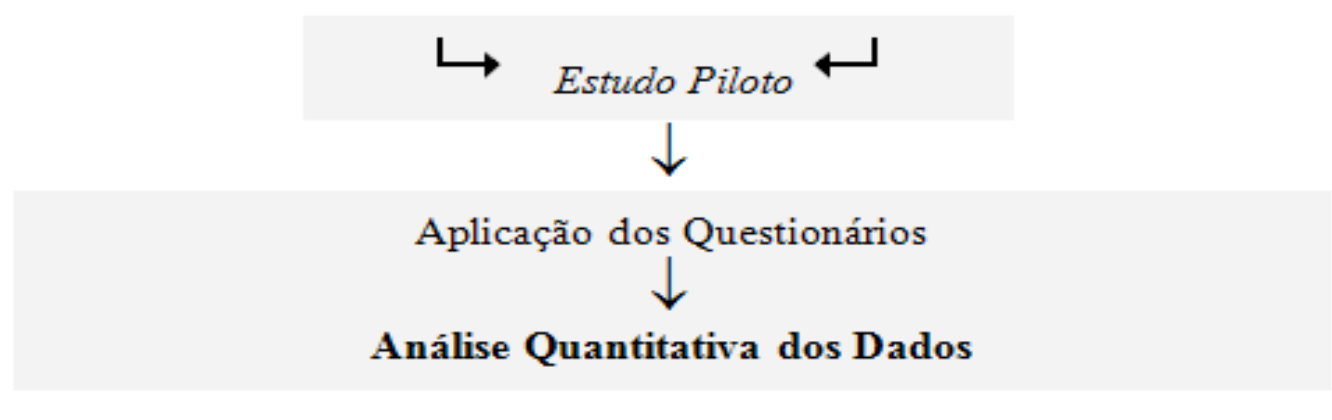

Cálculo da Amostra

(para população finita)

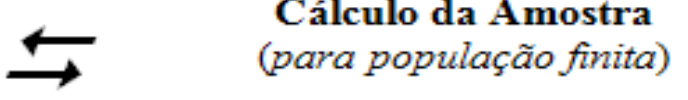

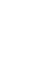

Fonte: elaboração própria 
Quadro 1: Classificação das Variáveis do Estudo

\begin{tabular}{|c|c|c|c|}
\hline Variável & Natureza & Classificação & Comentários \\
\hline Curso matriculado & Qualitativa & Ordinal & $\begin{array}{l}\text { Pode-se estabelecer ordenação } \\
\text { (especialização, mestrado, etc.) }\end{array}$ \\
\hline Graduação (área) & Qualitativa & Nominal & Não possui ordenação \\
\hline $\begin{array}{l}\text { Relação entre } \\
\text { Graduação e pós }\end{array}$ & Qualitativa & Nominal & Não possui ordenação \\
\hline $\begin{array}{c}\text { Trabalho rural na } \\
\text { família }\end{array}$ & Qualitativa & Nominal & Não possui ordenação \\
\hline $\begin{array}{l}\text { Determinante da } \\
\text { escolha pela } \\
\text { Graduação }\end{array}$ & Qualitativa & Nominal & Não possui ordenação \\
\hline $\begin{array}{l}\text { Atividade } \\
\text { extraclasse }\end{array}$ & Qualitativa & Nominal & Não possui ordenação \\
\hline $\begin{array}{l}\text { Determinante da } \\
\text { escolha pela pós }\end{array}$ & Qualitativa & Nominal & Não possui ordenação \\
\hline Religião & Qualitativa & Nominal & Não possui ordenação \\
\hline Renda familiar & Quantitativa & Contínua & Valores podem ser fracionados \\
\hline $\begin{array}{l}\text { Anos de estudo por } \\
\text { tipo de escola }\end{array}$ & Quantitativa & Contínua & Valores podem ser fracionados \\
\hline Idade & Quantitativa & Contínua & Valores podem ser fracionados \\
\hline $\begin{array}{c}\text { Tempo de vivência } \\
\text { na extensão rural }\end{array}$ & Quantitativa & Contínua & Valores podem ser fracionados \\
\hline $\begin{array}{c}\text { Distância do local } \\
\text { de residência }\end{array}$ & Quantitativa & Contínua & Valores podem ser fracionados \\
\hline
\end{tabular}

Fonte: Elaboração própria.

determinante da escolha pelo curso de pós-graduação; h) religião e i) renda total da família. As variáveis contínuas compreendem: j) anos de estudo do ensino médio em escolas públicas e privadas; 1 ) idade; $m$ ) tempo de vivência na área de extensão rural; n) distância do local onde reside a família.

Segundo MUNDSTOCK, et al. (2006) e BARBETTA (2012), as variáveis de estudo podem ser classificadas conforme o Quadro 1. De forma geral, as variáveis quantitativas são aquelas representadas por valores numéricos, sendo discretas quando assumem unicamente números inteiros e, contínuas, quando passível de fracionamento. As qualitativas, ao contrário, não possuem valores numéricos e dividem-se em nominais (sem registro de ordenação entre categorias) e ordinais (com ordenação). As variáveis do presente estudo são, portanto, classificadas como descritas no Quadro 1.

\subsection{O cálculo da amostra}

Para a análise de dados foi utilizado o Programa Estatístico SPSS (Statistical Package for Social Sciences), versão 20.0. Cabe também ressaltar que o nível de significância utilizado no cálculo da amostra foi de 5,0\%. Os dados estão apresentados na forma tabular e gráfica. A população (público-alvo - N) pode ser definida como aquela constituída por alunos do Programa de Pós-Graduação em Extensão Rural da Universidade Federal de Santa Maria - UFSM, na condição de matriculados em seus respectivos cursos (Especialização - Residência Agrária, Mestrado e Doutorado). Registros acadêmicos secundários ${ }^{4}$ coletados sobre o público-alvo estão relacionados na Tabela 1 .

Com base nas características da população, a amostra (n) foi elaborada a partir do entendimento de população finita ${ }^{5}$, portanto, com amostra probabilística (aleatória) simples. Conforme Gil (2009), sua determinação compreende a seguinte estrutura:

$$
\begin{aligned}
& \mathrm{n}=\left[\left(\mathrm{s}^{2}\right) \text { p.q. } \mathrm{N}\right] /\left[\mathrm{e}^{2}(\mathrm{~N}-1)+\left(\mathrm{s}^{2}\right) \mathrm{p} \cdot \mathrm{q}\right] \\
& \text { onde, } \\
& \mathrm{n}=\text { tamanho da amostra (número de alu- }
\end{aligned}
$$
nos)

4. Os dados secundários foram disponibilizados pela Coordenação do Curso de Pós-Graduação em Extensão Rural da UFSM (PPGExR). 5. Segundo GIL (2009, p. 97), uma população é considerada finita quando a população pesquisada não supera 100.000 elementos. 
$\mathrm{s}^{2}=$ nível de confiança escolhido, expresso em número de desvios-padrão se verifica

$\mathrm{p}=$ percentagem com a qual o fenômeno

$\mathrm{q}=$ percentagem complementar $(100-\mathrm{p})$

$\mathrm{N}$ = tamanho da população (número total de formandos)

$\mathrm{e}^{2}=$ erro máximo permitido

Considerando a possibilidade de $5,0 \%$ de erro amostral $\left(\mathrm{e}^{2}\right)$, o cálculo da amostra, abaixo demonstrado, indicou a aplicação de 44 questionários na coleta dos dados primários. Os questionários foram aplicados entre os dias 11/11/2013 e $30 / 11 / 2013$, com pré-teste (estudo piloto) realizado entre os dias $03 / 10 / 2013$ e 15/10/2013, compreendendo, nesta etapa específica, 15 questionários. O cálculo amostral está representado abaixo:

$$
\begin{gathered}
\mathrm{n}=\left[(1,96)^{2} \cdot 0,95 \cdot 0,05 \cdot 112\right] /\left[(0,05)^{2} .\right. \\
\left.(112-1)+(1,96)^{2} \cdot 0,95 \cdot 0,05\right] \\
\mathrm{n}=[(3,8416 \cdot 0,95 \cdot 0,05 \cdot 112)] /[(0,0025 \\
.111)+(3,8416 \cdot 0,95 \cdot 0,05)] \\
\mathrm{n}=20,437312 / 0,459976 \\
\mathrm{n}=44,43125728(\cong \cong \text { 44alunos })
\end{gathered}
$$

Segundo BRUNI (2009), para números amostrais iguais ou superiores a $30(n \geq 30)$ a distribuição amostral é considerada normal. Testes visuais podem ser realizados pela análise da curva normal (conhecida de forma recorrente como a Curva de Gauss) ou, ao contrário, pelo teste Kolgomorov-Smirnov (KS), quando $\mathrm{n} \leq 30$. Para assegurar que os dados sejam normais, nos casos em que $n \geq 30$, realiza-se, neste estudo, o teste Qui-quadrado, explorado adiante. Sobre a característica da amostra, BRUNI (2009) indica que,

a Lei dos grandes números estabelece que, com o aumento do tamanho da amostra, a distribuição de frequências relativas da amostra se aproxima da distribuição de frequências da população. À medida que o tamanho da amostra cresce, a média amostral converge para a média populacional (BRUNI, 2009, p. 88).

Considerando a amostra obtida e a lei dos grandes números, torna-se, portanto, necessária a realização do teste Qui-quadrado na averiguação da amostra calculada ${ }^{6}$, uma vez que $n \geq 30$. Para

6. A realização do teste não-paramétrico (Chi-Square) para a variável contínua "idade" apresentou significância de 0,988 , enquanto que para a variável "anos de vivência na área de extensão rural", o resultado foi de 0,129 . divisão do número amostral entre os três cursos, utilizou-se os dados da Tabela 1 para a determinação proporcional dos questionários por turma. A Tabela 2 apresenta a divisão amostral.

A seleção dos respondentes obedeceu a sorteio por listagem de matriculados em cada curso de pós-graduação. Assim, os alunos foram numerados e, em seguida, o número de elementos da amostra proporcional (Tabela 2) foi determinado de forma aleatória. O conjunto de procedimentos metodológicos proposto, combinado com a escolha do questionário como técnica de coleta de dados, anteriormente destacada, possibilitou o alcance de importantes resultados sobre o público-alvo da pesquisa. Os resultados são a seguir apresentados.

\section{RESULTADOS E DISCUSSÕES}

\section{I Caracterização descritiva dos dados}

O perfil dos alunos do PPGExR está caracterizado pelo predomínio da formação profissional em ciências rurais, com $63,6 \%$ dos alunos. Observase que somente $38,6 \%$ possuem alguma religião, $25,0 \%$ a possuem, mas não praticam e $36,4 \%$ não possuem. O nível de renda está acima dos cinco salários mínimos para $61,4 \%$ dos respondentes. A idade média é de 34,3 anos. Durante o ensino médio, $79,5 \%$ frequentou ao menos um ano em escola pública e, para a escola privada, $43,2 \%$ se verifica. A Tabela 3 apresenta os mesmos elementos, porém, analisados por nível de pós-graduação (cross select).

Com exceção do curso de mestrado, é notório que nos demais cursos a área de formação difere daquelas relacionadas às ciências rurais. Em termos de religiosidade, os alunos dos cursos de especialização e doutorado apresentam os índices mais baixos. A média de idade dos alunos não difere muito do conjunto, em torno de 34 anos. Quanto ao ensino médio, há um percentual mais significativo de alunos que estudaram em escolas públicas no doutorado e na especialização.

\subsection{Determinantes das escolhas - a pesquisa social sobre o meio rural}

Entre os determinantes da escolha pela pesquisa social destinada ao meio rural, o registro familiar de trabalho representa importante elemento. É possível encontrar grande parcela de estudantes que possuem alguma relação familiar com atividades rurais. No doutorado, mestrado e especialização, os resultados apontam que, respectivamente, $25,0 \%, 58,3 \%$ e $65,0 \%$ dos alu- 
Tabela 1: População - Número De Alunos Por Curso

\begin{tabular}{c|c|c}
\hline Curso & Número de Alunos & Taxa Percentual (\%T) \\
\hline Especialização & 50 & 44,64 \\
\hline Mestrado & 30 & 26,79 \\
\hline Doutorado & 32 & 28,57 \\
\hline Total & $\mathbf{1 1 2}$ & $\mathbf{1 0 0}$ \\
\hline
\end{tabular}

Fonte: Coordenação de Curso.

Tabela 2: Aplicação Dos Questionários Por Curso

\begin{tabular}{c|c|c|c}
\hline Curso & $\begin{array}{c}\text { Número de } \\
\text { Alunos }\end{array}$ & Taxa Percentual (\%T) & $\begin{array}{c}\text { Número de Questionários } \\
\text { por Curso }\end{array}$ \\
\hline Especialização & 50 & 44,6 & 20 \\
\hline Mestrado & 30 & 26,8 & 12 \\
\hline Doutorado & 32 & 28,6 & 12 \\
\hline Total & $\mathbf{1 1 2}$ & $\mathbf{1 0 0}$ & $\mathbf{4 4}$ \\
\hline
\end{tabular}

Fonte: Tabela 1.

Tabela 3: Perfil Dos Alunos Da Pós-Graduação Por Curso

\begin{tabular}{l|c|c|c}
\hline \multicolumn{1}{c|}{ Variável } & Doutorado & Mestrado & Especialização \\
\hline Área de formação (\%) & $\begin{array}{c}\text { Ciências Sociais } \\
57,1\end{array}$ & $\begin{array}{c}\text { Ciências Rurais } \\
28,6^{*}\end{array}$ & $\begin{array}{c}\text { Ciências } \\
\text { Humanas 55,6 }\end{array}$ \\
\hline Não possui religião (em \%) & 36,4 & 33,3 & 50,0 \\
\hline Renda com mais de 5 sal. (em \%) & 75,0 & 66,7 & 50,0 \\
\hline Idade (média em anos) & 34,8 & 34,8 & 33,9 \\
\hline $\begin{array}{l}\text { Ensino médio (escola pública) (média } \\
\text { em anos) }\end{array}$ & 2,1 & 1,8 & 2,3 \\
\hline $\begin{array}{l}\text { Ensino médio (escola privada) (média } \\
\text { em anos) }\end{array}$ & 0,9 & 1,2 & 0,8 \\
\hline
\end{tabular}

Fonte: Dados da pesquisa. * Mesmo percentual se verifica para ciências sociais.

Tabela 4: Motivo Da Escolha Pelo Curso De Graduação Por Área

\begin{tabular}{l|c|c|c}
\hline \multicolumn{1}{c|}{ Motivação } & $\begin{array}{c}\text { Ciências } \\
\text { Humanas (\%) }\end{array}$ & $\begin{array}{c}\text { Ciências } \\
\text { Rurais (\%) }\end{array}$ & $\begin{array}{c}\text { Ciências } \\
\text { Sociais (\%) }\end{array}$ \\
\hline O sentido social da profissão & 77,8 & 28,6 & 42,9 \\
\hline Maior chance de ascensão social/econômica & 0,0 & 7,1 & 0,0 \\
\hline Vocação & 11,1 & 46,4 & 28,6 \\
\hline Influência de amigos ou familiares & 0,0 & 17,9 & 28,6 \\
\hline Falta de oportunidade em outras áreas & 11,1 & 0,0 & 0,0 \\
\hline
\end{tabular}

Fonte: Dados da pesquisa. 
Tabela 5: Atividades Extraclasse Na Graduação Por Nível

\begin{tabular}{l|c|c|c}
\hline \multicolumn{1}{c|}{ Motivação } & $\begin{array}{c}\text { Doutorado } \\
\mathbf{( \% )}\end{array}$ & Mestrado (\%) & $\begin{array}{c}\text { Especialização } \\
\text { (\%) }\end{array}$ \\
\hline Extensão & 25,0 & 50,0 & 30,0 \\
\hline Movimento estudantil & 16,7 & 25,0 & 45,0 \\
\hline Pesquisa e estágio & 50,0 & 16,7 & 25,0 \\
\hline Monitoria & 8,3 & 8,3 & 0,0 \\
\hline
\end{tabular}

Fonte: Dados da pesquisa.

nos possuem atualmente vínculos familiares de trabalho com a realidade rural. De outro lado, como demonstrado na Tabela 4, a análise crosstab da escolha por cursos de graduação dos atuais pós-graduandos relaciona-se com propriedade ao sentido de social da profissão para os graduados em ciências humanas e sociais. Para os cursos de ciências rurais, embora a porcentagem desta alternativa não seja desprezível $(28,6 \%)$, a maioria indica a vocação como principal motivo da escolha profissional $(46,4 \%)$.

Durante o período de formação profissional, as atividades extraclasses de interesse dos atuais pós-graduandos estão assinaladas na Tabela 5. Dessa forma, os atuais alunos de doutorado envolveram-se mais efetivamente com pesquisa durante a graduação $(50,0 \%)$ quando comparados com os demais. Mestrandos participaram mais fortemente com atividades de extensão, enquanto que, para os alunos de especialização, as atividades relacionadas ao movimento estudantil somam $45,0 \%$ do total.

A análise de correlação de Pearson ${ }^{7}$, com significância de $1 \%$, permite verificar um coeficiente de 0,5 entre as variáveis 'idade' e 'anos de estudo em escola pública'. Embora trate-se de uma correlação positiva fraca, aponta para o fato de que alunos com idade mais avançada frequentaram escolas públicas por um período maior quando comparados com os de menor idade. Ainda se

\footnotetext{
7. Segundo MUNDSTOCK, et al. (2006), o coeficiente de Pearson representa uma medida que pode variar de -1 a +1 . Se positivo, existe relação direta entre as variáveis (valores altos de uma variável correspondem a valores altos de outra variável); se negativo, existe relação inversa entre as variáveis (valores altos de uma variável correspondem a valores baixos de outra variável). Quando nulo ou aproximadamente nulo, significa que não existe correlação linear. Dependendo do valor do coeficiente, o mesmo é classificado como fraco, médio ou forte. Para FIGUEIREDO FILHO \& SILVA JUNIOR (2009, p. 115), no entanto, não há consenso quanto a classificação exata dos coeficientes. Segundo os autores, o certo é que quanto mais perto de 1 (independente do sinal) maior é o grau de dependência estatística linear entre as variáveis. No outro oposto, quanto mais próximo de zero, menor é a força dessa relação.
}

pode verificar que - com um índice de correlação positiva de 0,7 , que o avanço da idade está fortemente correlacionado com os anos de vivência na área de extensão rural. O coeficiente positivo de 0,4 (correlação fraca) permite inferir que alunos que estudaram em escolas públicas durante o ensino médio apresentam maior tempo de vivência com extensão rural.

A Figura 2 oferece a média dos anos de vivência em extensão rural distribuída pela área escolhida durante a graduação. Observa-se que a média dos alunos oriundos das ciências rurais apresentam uma média de anos de vivência superior às demais áreas, o que leva a inferir que os alunos oriundos das ciências rurais vieram a atuar no mercado de trabalho antes de ingressarem na pós graduação.

A Figura 3 por sua vez vem a colaborar com os resultados da Figura 2, a partir do momento que compreende-se que os alunos do mestrado são provenientes em sua maioria das Ciências Rurais, logo, desempenharam atividades profissionais antes de realizarem os estudos de pós-graduação. Da mesma forma, os alunos do doutorado apresentam a menor média de anos de vivência, devido à maior parte deste advirem da área das Ciências sociais, possuem poucos anos de vivência, o que leva a inferir que não chegaram a atuar profissionalmente; após concluir os estudos da graduação seguiram com os estudos na pós-graduação.

$\mathrm{Na}$ análise dos determinantes pela escolha do PPGExR, foi possível identificar que o "conceito do curso" determinou 88,9\% dos casos de alunos oriundos da área de ciências rurais. A representação dos alunos das ciências humanas variou igualmente $(33,3 \%)$ entre as opções "qualificação dos docentes do programa" e "indicação da empresa em que trabalha". No caso dos alunos formados nas ciências sociais, a escolha pelo PPGExR se deu principalmente $(60,0 \%)$ pela proximidade do local de residência.

Os dados revelam que a média de idade dos pós-graduandos que foram motivados pelo 


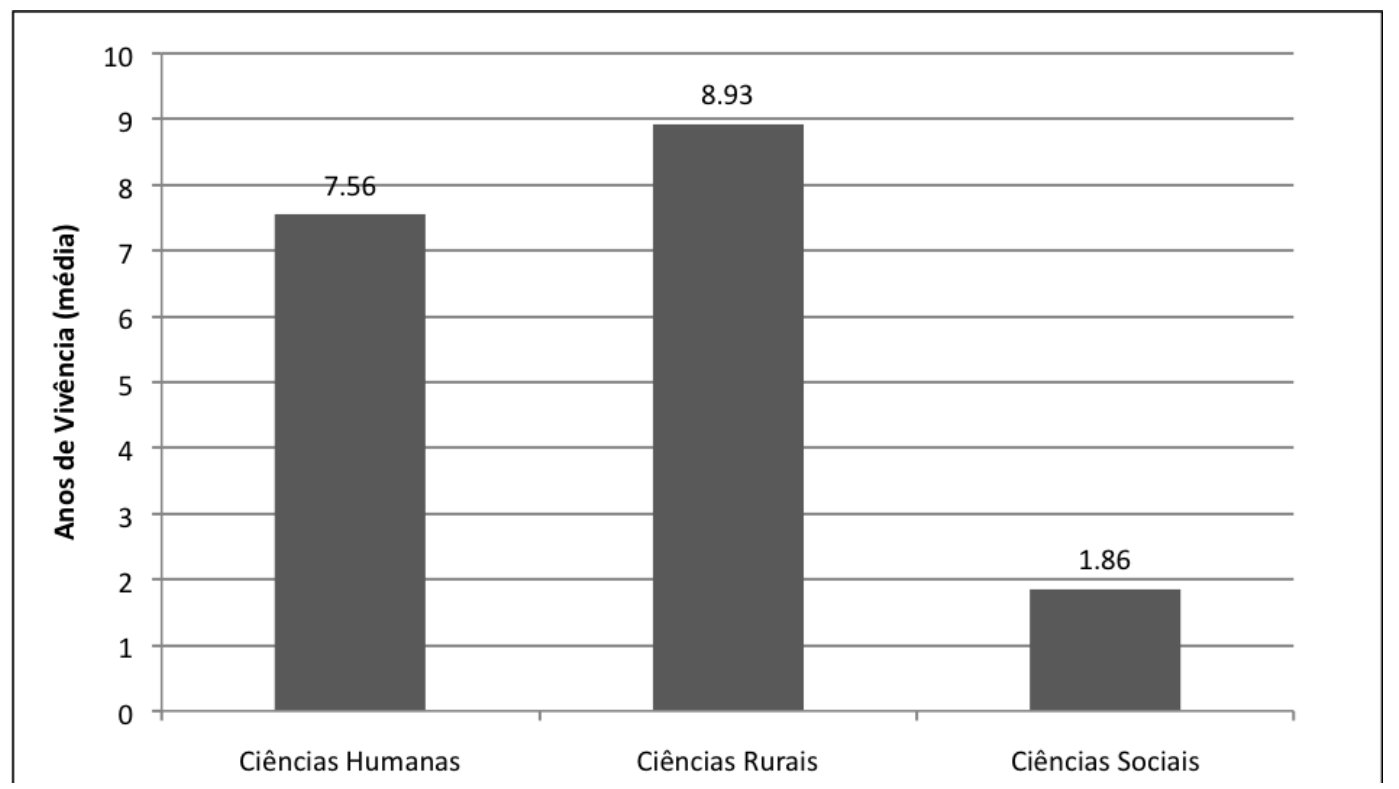

Figura 2. Anos de vivência em extensão rural distribuídos pela área escolhida durante a graduação.

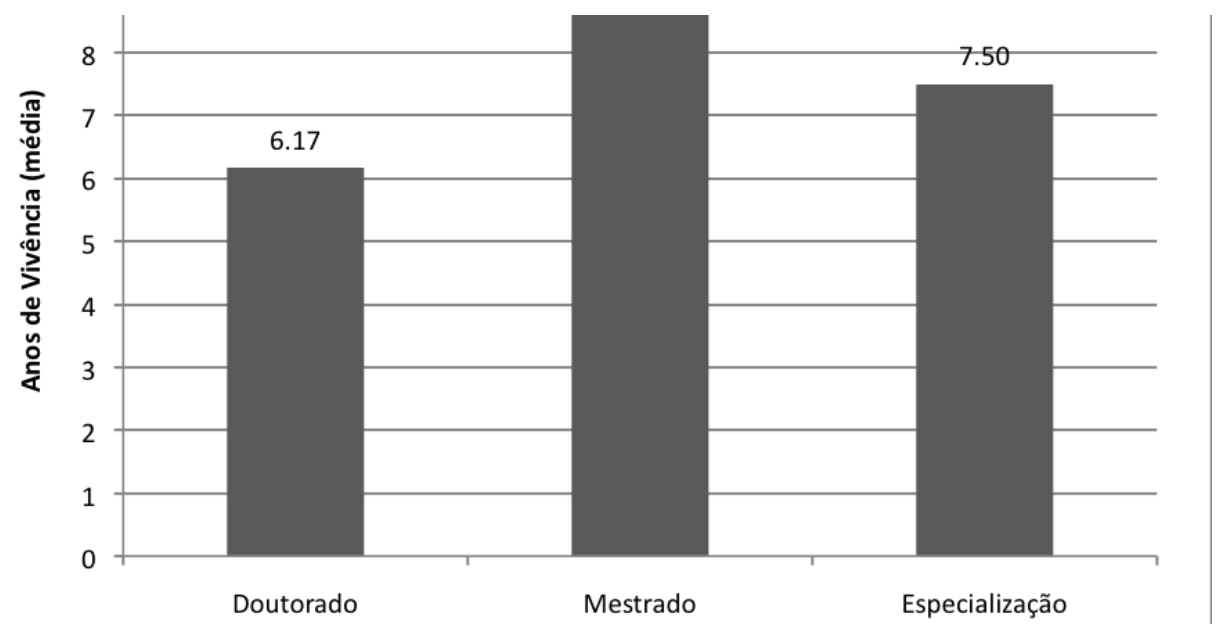

Figura 3. Anos de vivência em extensão rural distribuídos pelo nível de pós-graduação.

Tabela 6: Distância Entre Residência E Curso De Pós-Graduação

\begin{tabular}{c|c|c|c}
\hline Quilômetros & Doutorado (\%) & Mestrado (\%) & Especialização (\%) \\
\hline Menos de 50 & 50,0 & 33,3 & 30,0 \\
\hline Entre 50,1 e 100 & 16,7 & 8,3 & 10,0 \\
\hline Entre 100,01 e 200 & - & - & - \\
\hline Entre 200,01 e 300 & 8,3 & 16,7 & 30,0 \\
\hline Entre 300,01 e 500 & 8,3 & 8,3 & 5,0 \\
\hline Entre 500,01 e 600 & 8,3 & 16,7 & 5,0 \\
\hline Mais de 600 & 8,3 & 16,7 & 20,0 \\
\hline
\end{tabular}

Fonte: Dados da pesquisa. 
"conceito do programa" é superior (35 anos) àquelas médias das demais respostas. A alternativa "indicação da empresa que trabalha", por outro lado, apresenta a média de idade mais alta, 50 anos. A mesma ferramenta estatística demonstrou que a distância média entre o local de residência e o PPGExR é de 746,7 Km para os alunos que entendem a pós-graduação como "uma área que se aproxima em parte do que foi estudado na graduação". Em outro extremo, a distância média de $223 \mathrm{Km}$ relaciona-se à opção "uma continuidade dos estudos da graduação".

A Tabela 6 aponta especificamente a distância entre a residência do aluno e o PPGExR por curso de pós-graduação em que está matriculado, em porcentagens de ocorrência. A média geral da amostra é de $353,02 \mathrm{Km}$, com desvio padrão de 517,08 . A moda encontrada é de zero, seu mínimo. A distância máxima encontrada é de $2.500 \mathrm{Km}$. Os dados permitem verificar que o curso de doutorado contém o maior número de alunos que residem em local próximo ao PPGExR. No mestrado e na especialização, observa-se uma distribuição mais equilibrada entre as distâncias.

Por fim, Tabela 7 apresenta quatro elementos sobre o que a pós-graduação representa para o futuro profissional dos estudantes. No doutorado as respostas apresentaram-se divididas e, no curso de mestrado, mais concentradas nas alternativas "Área de pesquisa próxima com o que estudou durante a graduação" e "Aprofundamento na área de trabalho". Nesta última encontra-se 65,0\% dos alunos de especialização em Residência Agrária.

A mesma avaliação, observada por área de formação, mostra que, para os alunos da área de ciências rurais, $64,3 \%$ consideram sua pós-graduação como um aprofundamento na área de trabalho. Para $85,7 \%$ dos profissionais de ciências sociais, o PPGExR é uma área de pesquisa próxima da área de origem. A Tabela 8 indica os percentuais.

Tabela 7: O Que Representa Seu Curso De Pós-Graduação/Nível

\begin{tabular}{l|c|c|c}
\hline \multicolumn{1}{c|}{ Resposta } & $\begin{array}{c}\text { Doutorado } \\
\text { (\%) }\end{array}$ & $\begin{array}{c}\text { Mestrado } \\
\text { (\%) }\end{array}$ & $\begin{array}{c}\text { Especialização } \\
\text { (\%) }\end{array}$ \\
\hline $\begin{array}{l}\text { Continuidade dos estudos da } \\
\text { graduação }\end{array}$ & 16,7 & 0,0 & 15,0 \\
\hline Novo campo de conhecimento & 25,0 & 16,7 & 10,0 \\
\hline $\begin{array}{l}\text { Área de pesquisa próxima com o que } \\
\text { estudou durante a graduação }\end{array}$ & 33,3 & 41,7 & 10,0 \\
\hline Aprofundamento na área de trabalho & 25,0 & 41,7 & 65,0 \\
\hline
\end{tabular}

Fonte: Dados da pesquisa.

Tabela 8: O Que Representa Seu Curso De Pós-Graduação/Área

\begin{tabular}{l|c|c|c}
\hline \multicolumn{1}{c|}{ Resposta } & $\begin{array}{c}\text { Ciências } \\
\text { Humanas (\%) }\end{array}$ & $\begin{array}{c}\text { Ciências } \\
\text { Rurais (\%) }\end{array}$ & $\begin{array}{c}\text { Ciências } \\
\text { Sociais (\%) }\end{array}$ \\
\hline $\begin{array}{l}\text { Continuidade dos estudos da } \\
\text { graduação }\end{array}$ & 22,2 & 10,7 & - \\
\hline Novo campo de conhecimento & 22,2 & 14,3 & 14,3 \\
\hline $\begin{array}{l}\text { Área de pesquisa próxima com o que } \\
\text { estudou durante a graduação }\end{array}$ & 22,2 & 10,7 & 85,7 \\
\hline Aprofundamento na área de trabalho & 33,3 & 64,3 & - \\
\hline
\end{tabular}

Fonte: Dados da pesquisa. 


\section{CONCLUSÕES}

A maioria dos alunos é oriunda de cursos de ciências rurais, não possui religião e apresenta renda superior a cinco salários mínimos. Verificouse o predomínio da escola pública na formação principal dos alunos e elevado registro de trabalho rural na família. Para os formados em ciências rurais, a vocação parece representar o grande motivo pela escolha profissional. Doutorandos apontam a pesquisa como atividade extraclasse predominante, enquanto mestrados indicam a extensão e alunos de especialização o movimento estudantil. Este resultado particular parece corresponder, especialmente, com os objetivos de um curso de doutorado - baseado plenamente na pesquisa. $\mathrm{O}$ aprofundamento na área de trabalho é registrado como motivo principal da escolha pela pós-graduação entre os estudantes da especialização, o que se soma aos trabalhos relacionados ao movimento estudantil, durante a graduação.

Espera-se que o conhecimento acerca do perfil dos alunos de pós-graduação e suas escolhas quanto à pesquisa do mundo social-rural contribua para (i) melhor compreender o interesse de profissionais graduados em diferentes áreas; (ii) elucidar o quanto promissora é a interface entre distintas áreas de pesquisa e o enfoque social do mundo rural e, por fim, (iii) evidenciar dados importantes aos cursos que formam professores e pesquisadores.

O conjunto de dados apresentado neste trabalho representa uma importante interpretação sobre o perfil e os determinantes das escolhas dos alunos pela pesquisa social no meio rural. A falta de literatura acadêmica sobre o perfil dos alunos que se dedicam à pesquisa social voltada ao meio rural representou, ao mesmo tempo, uma dificuldade e uma motivação para este estudo. Percebe-se que o viés quantitativo, empregado na pesquisa, privilegia a objetividade dos resultados, ao mesmo tempo em que permite a exploração de evidências particulares e pontuais acerca do fenômeno. Considera-se, portanto, que outras pesquisas possam contribuir para o entendimento e caracterização deste público, tanto pela análise quantitativa como por meio da qualitativa - sendo mesmo possível a combinação de ambas.

A aplicação de questionários como instrumento principal de pesquisa se mostrou eficiente. Registra-se, no entanto, o quanto criterioso e cuidadoso deve ser o trabalho de seleção de variáveis e elaboração do instrumento, fase esta imediatamente anterior à testagem e ao trabalho de campo. A determinação da amostra probabilística conside- rou uma população finita e, seu cálculo,indicou a aplicação da pesquisa em cerca de $40,0 \%$ da população. Embora o estudo quantitativo tenha sido conduzido por meio de interpretações que se basearam em números e indicadores, o conjunto de variáveis assumido reuniu uma grande número de variáveis categóricas nominais, o que possibilitou a análise de questões diversas (não somente de variáveis contínuas).

\section{REFERÊNCIAS BIBLIOGRÁFICAS}

BARBETTA, P.Estatística aplicada às ciências sociais. Florianópolis: Ed. UFSC, 2012.

BRUNI, A. SPSS aplicado à pesquisa acadêmica. São Paulo: Atlas, 2009.

CHIZZOTTI, A. Pesquisa em ciências humanas e sociais. São Paulo: Cortez, 1995.

A pesquisa qualitativa em ciências humanas e sociais: evolução e desafios. Revista Portuguesa de Educação, v. 16, n. 2. Portugal:Universidade do Minho, 2003.

DESLANDES, S. Concepções em pesquisa social: articulações com o campo da avaliação em serviços de saúde. Cadernos de Saúde Pública, Rio de Janeiro, 1997.

FIGUEIREDO FILHO; SILVA JUNIOR. Desvendando os mistérios do coeficiente de

correlação de pearson (r). Revista Política Hoje, vol. 18, n. 1, 2009.

FREITAS, C. et al. Material de referência para o curso 1 de estatística. INPE. São José dos Campos, 2003.

FREITAS, H.; MOSCAROLA, J. Da observação à decisão: métodos de pesquisa e de análise quantitativa e qualitativa de dados. São Paulo. RAE, v. 1, n. 1 , jan-jun/2002.

GIL, A. Métodos e técnicas de pesquisa social. São Paulo: Atlas, 2009.

GRAY, D. E. Pesquisa no mundo real. 2. ed. Porto Alegre: Penso, 2012. 488 p.

MARSIGLIA, R. Orientações básicas para a pesquisa. In: MOTA, A. et al. Serviço Social e Saúde: 
formação e trabalho profissional. São Paulo: OPAS, OMS, Ministério da Saúde, 2007.

MUNDSTOCK, E. et al Introdução à análise estatística utilizando o SPSS 13.0. Cadernos de Matemática e Estatística. UFRGS. Número XX. Porto Alegre - maio de 2006.

UNIVERSIDADE FEDERAL DE SANTA

MARIA. Discentes. Santa Maria, 2013. Disponível em: < http://www.ppgexr.com.br/discentes.php>. Acesso em: 16 out. 2013.

UNIVERSIDADE FEDERAL DO ESTADO DO RIO GRANDE DO SUL. Discentes. Porto Alegre, 2013. Disponível em: < http://www.ufrgs.br/agronomia/joomla/index.php/ppgagro-o-programa> . Acesso em: 16 out. 2013.

UNIVERSIDADE FEDERAL DO ESTADO DO RIO GRANDE DO SUL. O Programa. Porto Alegre, 2013. Disponível em: < http://www.ufrgs.br/ pgdr/>. Acesso em: 16 out. 2013. 